\title{
ANALISIS FAKTOR YANG MEMENGARUHI PEMERIKSAAN ANC PADA IBU HAMIL DI WILAYAH PUSKESMAS ALAI KOTA PADANG TAHUN 2021
}

\author{
Mariana Br Harahap $^{* 1}$, Razia Begum Suroyo ${ }^{2}$, Mey Elisa Safitri ${ }^{3}$ \\ 1,2,3 Institut Kesehatan Helvetia, Medan \\ Email: 19anaharahap90@gmail.com, ${ }^{3}$ meyelisa@helvetia.ac.id
}

\begin{abstract}
Abstrak
Upaya percepatan penurunan AKI dilakukan dengan menjamin agar setiap ibu mampu mengakses pelayanan kesehatan ibu hamil melau ANC. Tujuan penelitian untuk menganalisis faktor yang memengaruhi pemeriksaan ANC pada ibu hamil di wilayah Puskesmas Alai Kota Padang. Jenis penelitian ini mixed method bentuk kualitatif dan kuantitatif. Populasi 112 orang dengan sampel menggunakan rumus slovin sebanyak 53 responden, sedangkan informan kualitatif terdiri dari 2 ibu hamil, 2 suami, 2 bidan serta 1 kepala puskesmas. Analisis data kuantitatif dengan analisis univariat, bivariat dan multivariat dengan menggunakan regresi binary logistik. Analisis data kualitatif meliputi reduksi data, penyajian data serta menarik kesimpulan. Hasil penelitian diperoleh variabel paritas $\mathrm{p}=0,035$, pendidikan $\mathrm{p}=0,001$, pekerjaan $\mathrm{p}=0,012$, penghasilan keluarga $\mathrm{p}=0,806$, jarak pelayanan kesehatan $\mathrm{p}=0,005$, dukungan suami $\mathrm{p}=0,002$, fasilitas pelayanan kesehatan $\mathrm{p}=0,000$ dan peran tenaga kesehatan $\mathrm{p}=0,003$. Pada analisis multivariat yang paling berpengaruh yaitu fasilitas pelayanan kesehatan dengan $\mathrm{p}=0.001$ dan dukungan suami $\mathrm{p}=0.003$. Secara kualitatif kurangnya dukungan suami yang menyebabkan ibu tidak melakukan pemeriksaan ANC, fasilitas pelayanan kesehatan di Puskesmas Alai telah memadai namun jarak pelayanan kesehatan yang jauh serta kondisi pandemi yang juga menyebabkan ibu tidak melakukan pemeriksaan ANC. Kesimpulan dalam penelitian ini bahwa fasilitas pelayanan kesehatan serta dukungan suami merupakan faktor yang paling dominan pengaruhnya terhadap kunjungan ANC. Disarankan kepada Puskesmas Alai agar mengoptimalkan fasilitas pelayanan ibu hamil untuk tercapainya kesejahteraan ibu dan bayi, suami agar memberikan dukungan kepada ibu hamil untuk melakukan pemeriksaan ANC.
\end{abstract}

Kata Kunci : Paritas, Pendidikan, Pekerjaan, Penghasilan Keluarga, Jarak Pelayanan Kesehatan

\begin{abstract}
Efforts to accelerate the decline in MMR are carried out by ensuring that every mother is able to access health services for pregnant women through ANC. The purpose of the study was to analyze the factors that influence the ANC examination in pregnant women in the Alai Health Center area of Padang City. This type of research is a mixed method in the form of qualitative and quantitative. The population of 112 people with a sample using the slovin formula as many as 53 respondents, while the qualitative informants consisted of 2 pregnant women, 2 husbands, 2 midwives and 1 head of the puskesmas. Analysis of quantitative data with univariate, bivariate and multivariate analysis using binary logistic regression. Qualitative data analysis includes data reduction, data presentation and drawing conclusions. The results showed that parity variable $p=0.035$, education $p=0.001$, occupation $p=0.012$, family income $p=0.806$, distance from health services $p=0.005$, husband's support $p=0.002$, health care facilities $p=0.000$ and the role of health workers $p=0.003$. In the multivariate analysis the most influential were health care facilities with $p=0.001$ and husband's support $p=0.003$. Qualitatively, the lack of husband's support causes mothers not to do ANC checks, the health service facilities at the Alai Health Center are adequate but the distance of health services is far and the pandemic condition also
\end{abstract}


causes mothers not to do ANC checks. The conclusion in this study is that health care facilities and husband's support are the most dominant factors influencing ANC visits. It is recommended to the Alai Health Center to optimize the service facilities for pregnant women to achieve the welfare of mothers and babies, husbands to provide support to pregnant women to carry out ANC checks.

Keywords: Parity, Education, Employment, Family Income, Health Service Distance

\section{Pendahuluan}

Angka Kematian Ibu (AKI) merupakan salah satu indikator untuk melihat derajat kesehatan perempuan sekaligus menjadi salah satu komponen indeks pembangunan maupun indeks kualitas hidup (Sumarmi, 2017). Penurunan AKI Pasca MDG's, World Health Organization (WHO) menetapkan agenda baru pembangunan kelanjutan dengan menetapkan SDG's (Sustainable Development Goals). Dalam SDG's, target penurunan AKI secara global di tahun 2030 adalah 70 per 100.000 kelahiran hidup (Kementerian Keseharan RI, 2015).

Upaya percepatan penurunan AKI dilakukan dengan menjamin agar setiap ibu mampu mengakses pelayanan kesehatan ibu yang berkualitas salah satunya pelayanan kesehatan ibu hamil. Penilaian terhadap pelaksanaan pelayanan kesehatan ibu hamil dapat dilakukan dengan melihat cakupan K1 dan K4 (Prabhakara, 2020).

Laporan WHO tahun 2018 Angka Kematian Ibu (AKI) di dunia sebanyak 289.000 jiwa. Di Amerika Serikat sebanyak 93.000 jiwa, di Afrika Utara sebanyak 179.000 jiwa, dan Asia Tenggara berjumlah 16.000 jiwa. Angka Kematian Ibu di negaranegara Asia Tenggara yaitu Indonesia 214 per 100.000 kelahiran hidup yang menduduki peringkat ke-3 dalam negara anggota ASEAN, Filipina 170 per 100.000 kelahiran hidup, Vietnam 160 per 100.000 kelahiran hidup, Thailand 144 per 100.000 kelahiran hidup, Brunei 60 per 100.000 kelahiran hidup dan Malaysia 39 per 100.000 kelahiran hidup (WHO, 2018).

Menurut Profil Kesehatan Indonesia Tahun 2019 secara umum terjadi penurunan kematian ibu selama periode 1991-2015 dari 390 menjadi 305 per 100.000 kelahiran hidup. Walaupun terjadi kecenderungan penurunan AKI, namun tidak berhasil mencapai target MDGs yang harus dicapai yaitu sebesar 102 per 100.000 kelahiran hidup pada tahun 2015. Hasil supas tahun 2015 memperlihatkan AKI tiga kali lipat dibandingkan target MDGs. Jumlah kematian ibu menurut provinsi tahun 2018-2019 dapat dilihat dimana terdapat penurunan dari 4.226 menjadi 4.221 kematian ibu d Indonesia berdasarkan laporan. Pada tahun 2019 penyebab kematian ibu terbanyak adalah perdarahan (1.280) kasus), hipertensi dalam kehamilan (1.066 kasus), infeksi (207 kasus) (Prabhakara, 2020).

Data Profil Kesehatan Dinas Kesehatan Provinsi Sumatera Barat Tahun 2017 kasus kematan ibu berjumlah 115 kasus, mengalami penurunan pada tahun 2016 yaitu berjumlah 107 kasus. Rincian kematian ibu ini terdiri atas kematian ibu hamil sebanyak 23 orang, kematian ibu bersalin sebanyak 56 orang, dan kematian ibu nifas sebanyak 36 orang. Kabupaten/kota penyumbang angka kematian ibu tertinggi yaitu Kabupaten Pasaman Barat dan Kota Padang (Kementerian Kesehatan Ri, 2017). 
Data dari Puskesmas Alai didapatkan pada tahun 2018 persentase K1 sebesar 93,3\% (447 orang) dan K4 sebesar 92,1\% (446 orang). Pada tahun 2019 persentase K1 dan K4 sebesar 98,1 (473 orang). Sedangkan pencapaian kunjungan K1 di Puskesmas Alai pada tahun 2020 sebesar $90,4 \%$, belum memenuhi target Nasional untuk kunjungan 95\% K1 dan kunjungan K4 sebesar 87,9\% belum memenuhi target Nasional untuk kunjungan $95 \% \mathrm{~K} 4$.

Menurut Pedoman Pelayanan Antenatal, Persalinan, Nifas, dan Bayi Baru Lahir di era adaptasi kebiasaan baru pelayanan antenatal (Antenatal Care/ANC) pada kehamilan normal minimal 6x dengan rincian $2 \mathrm{x}$ di Trimester $1,1 \mathrm{x}$ di Trimester 2 , dan $3 \mathrm{x}$ di Trimester 3. Minimal 2x diperiksa oleh dokter saat kunjungan 1 di Trimester 1 dan saat kunjungan ke 5 di Trimester 3 (Kementerian Kesehatan RI, 2013).

Berdasarkan studi pendahuluan yang dilakukan di Puskesmas Alai pada tanggal 24 Mei 2021 didapatkan data bahwa dari 7 ibu hamil Trimester III yang tidak memeriksakan kehamilannya, 2 responden mengatakan dengan alasan belum sempat karena sibuk bekerja, 2 responden mengatakan belum mengetahui pentingnya pemeriksaan kehamilan, 1 responden mengatakan karena suami tidak ada waktu untuk mengantarkan periksa dan 2 responden mengatakan kehamilannya adalah hal biasa yang akan dihadapi oleh setiap wanita sehingga tidak perlu dilakukan pemeriksaan khusus, terutama pada ibu yang sudah memiliki lebih dari 1 orang anak dan tidak mengalami keluhan selama hamil.

\section{Metode Penelitian}

Desain penelitian ini menggunakan mixed method merupakan pendekatan dengan mengkombinasikan atau mengasosiasikan bentuk kualitatif dan bentuk kuantitatif. Spesifikasi penelitian kuantitatif yang digunakan pada penelitian ini adalah metode analitik komparatif dengan pendekatan cross sectional. Strategi metode campuran yang digunakan dalam penelitian ini adalah strategi eksplanatoris sekuensial. Strategi ini diterapkan dengan pengumpulan dan analisis data kuantitatif pada tahap pertama yang diikuti oleh pengumpulan dan analisis data kualitatif pada tahap kedua yang dibangun berdasarkan hasil awal kuantitatif (9).

Populasi 112 orang dengan sampel menggunakan rumus slovin sebanyak 53 responden, sedangkan informan kualitatif terdiri dari 2 ibu hamil, 2 suami, 2 bidan serta 1 kepala puskesmas. Analisis data kuantitatif dengan analisis univariat, bivariat dan multivariat dengan menggunakan Regresi binary logistic. Analisis data kualitatif meliputi reduksi data, penyajian data serta menarik kesimpulan. 


\section{MIRACLE JOURNAL}

\section{Hasil dan Pembahasan}

\section{Analisis Univariat}

Tabel 1. Distribusi Frekuensi Analisis Faktor Yang Memengaruhi Pemeriksaan ANC Pada Ibu Hamil Di Wilayah Puskesmas Alai Kota Padang Tahun 2021

\begin{tabular}{|c|c|c|}
\hline Variabel & $\mathrm{f}$ & Persentase \\
\hline \multicolumn{3}{|l|}{ Paritas } \\
\hline Banyak & 32 & 60,4 \\
\hline Sedikit & 21 & 39,6 \\
\hline \multicolumn{3}{|l|}{ Pendidikan Ibu } \\
\hline Tinggi & 20 & 37,7 \\
\hline Menengah & 25 & 47,2 \\
\hline Dasar & 8 & 15,1 \\
\hline \multicolumn{3}{|l|}{ Pekerjaan Ibu } \\
\hline Bekerja & 30 & 56,6 \\
\hline Tidak Bekerja & 23 & 43,4 \\
\hline \multicolumn{3}{|l|}{ Penghasilan Keluarga } \\
\hline Diatas UMR & 32 & 60,4 \\
\hline Dibawah UMR & 21 & 39,6 \\
\hline \multicolumn{3}{|c|}{ Jarak Pelayanan Kesehatan } \\
\hline Jauh & 20 & 37,7 \\
\hline Dekat & 33 & 62,3 \\
\hline \multicolumn{3}{|l|}{ Dukungan Suami } \\
\hline Mendukung & 23 & 43,4 \\
\hline Tidak Mendukung & 30 & 56,6 \\
\hline \multicolumn{3}{|c|}{ Fasilitas Pelayanan Kesehatan } \\
\hline Baik & 26 & 49,1 \\
\hline Kurang Baik & 27 & 50,9 \\
\hline \multicolumn{3}{|l|}{ Peran Tenaga Kesehatan } \\
\hline Mendukung & 22 & 41,5 \\
\hline Tidak Mendukung & 31 & 58,5 \\
\hline \multicolumn{3}{|l|}{ Kunjungan ANC } \\
\hline Lengkap & 20 & 37,7 \\
\hline Tidak Lengkap & 33 & 62,3 \\
\hline
\end{tabular}

\section{Analisis Bivariat}

Tabel 2 Hubungan Paritas Ibu Terhadap Kunjungan Antenatal Care Di Puskesmas Alai

\begin{tabular}{|c|c|c|c|c|c|c|c|}
\hline \multirow{3}{*}{ Paritas Ibu } & \multicolumn{4}{|c|}{ Kunjungan ANC } & \multirow{2}{*}{\multicolumn{2}{|c|}{ Jumlah }} & \multirow{3}{*}{$p($ Sig $)$} \\
\hline & \multicolumn{2}{|c|}{ Lengkap } & \multicolumn{2}{|c|}{ Tidak Lengkap } & & & \\
\hline & $f$ & $\%$ & $\mathrm{f}$ & $\%$ & $f$ & $\%$ & \\
\hline Banyak & 7 & 13.2 & 25 & 47.2 & 32 & 60.4 & \multirow{2}{*}{0,008} \\
\hline Sedikit & 13 & 24.5 & 8 & 15.1 & 21 & 39.6 & \\
\hline Total & 20 & 37.7 & 33 & 62.3 & 53 & 100 & \\
\hline
\end{tabular}




\section{MIRACLE JOURNAL}

Berdasarkan Tabel 2 dimana 60,4\% paritas yang >2 (banyak) lebih cenderung tidak lengkap melakukan pemeriksaan ANC yaitu 47,2\%.

Tabel 3. Hubungan Pendidikan Ibu Terhadap Kunjungan Antenatal Care Di Puskesmas Alai

\begin{tabular}{|c|c|c|c|c|c|c|c|}
\hline \multirow{3}{*}{ Pendidikan Ibu } & \multicolumn{4}{|c|}{ Kunjungan ANC } & \multirow{2}{*}{\multicolumn{2}{|c|}{ Jumlah }} & \multirow{3}{*}{$p($ Sig $)$} \\
\hline & \multicolumn{2}{|c|}{ Lengkap } & \multicolumn{2}{|c|}{ Tidak Lengkap } & & & \\
\hline & $\mathrm{F}$ & $\%$ & $\mathrm{f}$ & $\%$ & $\mathrm{f}$ & $\%$ & \\
\hline Tinggi & 15 & 28.3 & 5 & 9.4 & 20 & 37.7 & \multirow{3}{*}{0,000} \\
\hline Menengah & 3 & 5.7 & 22 & 41.5 & 25 & 47.2 & \\
\hline Dasar & 2 & 3.8 & 6 & 11.3 & 8 & 15.1 & \\
\hline Total & 20 & 37.8 & 33 & 62.2 & 53 & 100 & \\
\hline
\end{tabular}

Berdasarkan Tabel 3 dimana 37,7\% ibu yang berpendidikan tinggi hampir seluruhnya melakukan pemeriksaan ANC secara lengkap yaitu 28,3\% .

Tabel 4. Hubungan Pekerjaan Ibu Terhadap Kunjungan Antenatal Care Di Puskesmas Alai

\begin{tabular}{|c|c|c|c|c|c|c|c|}
\hline \multirow{3}{*}{ Pekerjaan Ibu } & \multicolumn{4}{|c|}{ Kunjungan ANC } & \multirow{2}{*}{\multicolumn{2}{|c|}{ Jumlah }} & \multirow{3}{*}{$p($ Sig $)$} \\
\hline & \multicolumn{2}{|c|}{ Lengkap } & \multicolumn{2}{|c|}{ Tidak Lengkap } & & & \\
\hline & $\mathrm{f}$ & $\%$ & $\mathrm{~F}$ & $\%$ & $\mathrm{f}$ & $\%$ & \\
\hline Bekerja & 16 & 30.2 & 14 & 26.4 & 30 & 56.6 & \\
\hline Tidak bekerja & 4 & 7.5 & 19 & 35.9 & 23 & 43.4 & 0,017 \\
\hline Total & 20 & 37.7 & 33 & 62.3 & 53 & 100 & \\
\hline
\end{tabular}

Berdasarkan Tabel 4 dimana 56,6\% ibu yang bekerja mayoritas yang kunjungan ANC nya lengkap yaitu 30,2\% melakukan pemeriksaan ANC.

Tabel 5. Hubungan Penghasilan Keluarga Terhadap Kunjungan Antenatal Care Di Puskesmas Alai

\begin{tabular}{|c|c|c|c|c|c|c|c|}
\hline \multirow{3}{*}{ Penghasilan Keluarga } & \multicolumn{4}{|c|}{ Kunjungan ANC } & \multirow{2}{*}{\multicolumn{2}{|c|}{ Jumlah }} & \multirow{3}{*}{$p($ Sig $)$} \\
\hline & \multicolumn{2}{|c|}{ Lengkap } & \multicolumn{2}{|c|}{ Tidak Lengkap } & & & \\
\hline & $\mathrm{f}$ & $\%$ & $\mathrm{~F}$ & $\%$ & $\mathrm{f}$ & $\%$ & \\
\hline Diatas & 13 & 24.5 & 19 & 35,9 & 32 & 60.4 & \\
\hline UMR & & & & & & & 0,806 \\
\hline Dibawah UMR & 7 & 13.2 & 14 & 26,4 & 21 & 39.6 & \\
\hline Total & 20 & 37.7 & 33 & 62.3 & 53 & 100 & \\
\hline
\end{tabular}

Berdasarkan Tabel 5 dimana 60,4\% penghasilan diatas UMR mayoritas melakukan pemeriksaan ANC secara tidak lengkap yaitu 35,9\%.

Tabel 6. Hubungan Jarak Pelayanan Kesehatan Terhadap Kunjungan Antenatal Care Di Puskesmas Alai

\begin{tabular}{|c|c|c|c|c|c|c|c|}
\hline \multirow{3}{*}{$\begin{array}{c}\text { Jarak Pelayanan } \\
\text { Kesehatan }\end{array}$} & \multicolumn{4}{|c|}{ Kunjungan ANC } & \multirow{2}{*}{\multicolumn{2}{|c|}{ Jumlah }} & \multirow{3}{*}{$p($ Sig $)$} \\
\hline & \multicolumn{2}{|c|}{ Lengkap } & \multicolumn{2}{|c|}{ Tidak Lengkap } & & & \\
\hline & $\mathrm{f}$ & $\%$ & $\mathrm{~F}$ & $\%$ & $\mathrm{f}$ & $\%$ & \\
\hline Jauh & 1 & 1.9 & 19 & 35.9 & 20 & 37.7 & 0,000 \\
\hline
\end{tabular}




\section{MIRACLE JOURNAL}

\begin{tabular}{|c|c|c|c|c|c|c|}
\hline Dekat & 19 & 35.9 & 14 & 26.4 & 33 & 62.3 \\
\hline Total & 20 & 37.8 & 33 & 62.3 & 53 & 100 \\
\hline
\end{tabular}

Berdasarkan Tabel 6 dimana 62,3\% < $5 \mathrm{~km}$ (dekat) mayoritas melakukan pemeriksaan ANC secara lengkap yaitu 35,9\%.

Tabel 7. Hubungan Dukungan Suami Terhadap Kunjungan Antenatal Care Di Puskesmas Alai

\begin{tabular}{|c|c|c|c|c|c|c|c|}
\hline \multirow{3}{*}{ Dukungan Suami } & \multicolumn{4}{|c|}{ Kunjungan ANC } & \multirow{2}{*}{\multicolumn{2}{|c|}{ Jumlah }} & \multirow{3}{*}{$p($ Sig $)$} \\
\hline & \multicolumn{2}{|c|}{ Lengkap } & \multicolumn{2}{|c|}{ Tidak Lengkap } & & & \\
\hline & $\mathrm{f}$ & $\%$ & $\mathrm{~F}$ & $\%$ & $\mathrm{~F}$ & $\%$ & \\
\hline Mendukung & 16 & 30.2 & 7 & 13.2 & 23 & 43.4 & \\
\hline Tidak Mendukung & 4 & 7.5 & 26 & 49.1 & 30 & 56.6 & 0,000 \\
\hline Total & 20 & 37.7 & 33 & 62.3 & 53 & 100 & \\
\hline
\end{tabular}

Berdasarkan Tabel 7 dimana 56,6\% suami tidak mendukung melakukan pemeriksaan ANC secara tidak lengkap yaitu 49,1\%.

Tabel 8. Hubungan Fasilitas Pelayanan Kesehatan Terhadap Kunjungan Antenatal Care Di Puskesmas Alai

\begin{tabular}{|c|c|c|c|c|c|c|c|}
\hline \multirow{3}{*}{$\begin{array}{c}\text { Fasilitas Pelayanan } \\
\text { Kesehatan }\end{array}$} & \multicolumn{4}{|c|}{ Kunjungan ANC } & \multirow{2}{*}{\multicolumn{2}{|c|}{ Jumlah }} & \multirow{3}{*}{$p($ Sig) } \\
\hline & \multicolumn{2}{|c|}{ Lengkap } & \multicolumn{2}{|c|}{ Tidak Lengkap } & & & \\
\hline & $\mathrm{f}$ & $\%$ & $\mathrm{f}$ & $\%$ & $\mathrm{f}$ & $\%$ & \\
\hline Baik & 18 & 34.0 & 8 & 15.1 & 26 & 49.1 & \multirow{2}{*}{0,000} \\
\hline Kurang Baik & 2 & 3.7 & 25 & 47.2 & 27 & 50.9 & \\
\hline Total & 20 & 37.7 & 33 & 62.3 & 53 & 100 & \\
\hline
\end{tabular}

Berdasarkan Tabel 8 dimana $49,1 \%$ fasilitas pelayanan baik mayoritas melakukan pemeriksaan ANC secara lengkap yaitu 34\%.

Tabel 9. Hubungan Peran Tenaga Kesehatan Terhadap Kunjungan Antenatal Care Di Puskesmas Alai

\begin{tabular}{|c|c|c|c|c|c|c|c|}
\hline \multirow{3}{*}{$\begin{array}{l}\text { Peran Tenaga } \\
\text { Kesehatan }\end{array}$} & \multicolumn{4}{|c|}{ Kunjungan ANC } & \multirow{2}{*}{\multicolumn{2}{|c|}{ Jumlah }} & \multirow{3}{*}{$p($ Sig $)$} \\
\hline & \multicolumn{2}{|c|}{ Lengkap } & \multicolumn{2}{|c|}{ Tidak Lengkap } & & & \\
\hline & $\mathrm{f}$ & $\%$ & $\mathrm{f}$ & $\%$ & $\mathrm{~F}$ & $\%$ & \\
\hline Mendukung & 15 & 28.3 & 7 & 13.2 & 22 & 41.5 & \multirow{2}{*}{0,000} \\
\hline Tidak Mendukung & 5 & 9.4 & 26 & 49.1 & 31 & 58.5 & \\
\hline Total & 20 & 37.7 & 33 & 62.3 & 53 & 100 & \\
\hline
\end{tabular}

Berdasarkan Tabel 8 dimana 58,5\% tidak mendukung melakukan pemeriksaan ANC secara tidak lengkap yaitu $49,1 \%$. 


\section{MIRACLE JOURNAL}

\section{Analisis Multivariat}

Tabel 10. Hasil Analisis Uji Multivariat Variabel Independen Terhadap Kunjungan ANC

\begin{tabular}{|c|c|c|c|c|c|c|}
\hline No. & $\begin{array}{c}\text { Variabel } \\
\text { Independen }\end{array}$ & Koefisien B & Wald & $\begin{array}{c}\text { OR } \\
{[\operatorname{Exp}(\beta)]}\end{array}$ & $\begin{array}{l}\text { CI. } 95 \% \text { for } \\
\operatorname{Exp}(B)\end{array}$ & $\mathrm{p}(\mathrm{Sig})$ \\
\hline 1. & Paritas & -3.176 & 4.486 & 0.042 & $0.002-0.741$ & 0.030 \\
\hline 2. & Pendidikan & 3.790 & 7.124 & 44.255 & $\begin{array}{c}2.737- \\
715.590\end{array}$ & 0.008 \\
\hline 3. & Pekerjaan & 3.812 & 5.733 & 45.249 & $\begin{array}{c}1.997- \\
1025.352\end{array}$ & 0.017 \\
\hline 4. & $\begin{array}{l}\text { Jarak Pelayanan } \\
\text { Kesehatan }\end{array}$ & -5.195 & 5.915 & 0.006 & $0.000-0.365$ & 0.015 \\
\hline 5. & Fasilitas Kesehatan & 3.533 & 7.770 & 34.231 & $\begin{array}{c}2.855- \\
410.502\end{array}$ & 0.005 \\
\hline 6. & Dukungan Suami & 3.989 & 8.110 & 53.982 & $\begin{array}{c}3.468- \\
840.215\end{array}$ & 0.004 \\
\hline 7. & $\begin{array}{l}\text { Peran Tenaga } \\
\text { Kesehatan }\end{array}$ & 2.792 & 5.075 & 16.307 & $\begin{array}{c}1.437- \\
185.009\end{array}$ & 0.024 \\
\hline
\end{tabular}

Berdasarkan Tabel 9 hasil uji multivariat dengan regersi binary logistic nilai variabel paritas $\mathrm{p}=0,035$, pendidikan $\mathrm{p}=0,001$, pekerjaan $\mathrm{p}=0,012$, penghasilan keluarga $p=0,806$, jarak pelayanan kesehatan $p=0,005$, dukungan suami $p=0,002$, fasilitas pelayanan kesehatan $\mathrm{p}=0,000$ dan peran tenaga kesehatan $\mathrm{p}=0,003$

Tabel 10

\section{Hasil Analisis Uji Multivariat Variabel Dukungan Suami Dan Peran Tenaga} Kesehatan Terhadap Kunjungan ANC

\begin{tabular}{clcccc}
\hline No. & Variabel Independen & Koefisien B & Wald & $\begin{array}{c}\text { OR } \\
{[\mathbf{E x p}(\boldsymbol{\beta})]}\end{array}$ & $\mathbf{p}(\mathbf{S i g})$ \\
\hline 1. & Fasilitas Pelayanan & 4.059 & 10.930 & 57.943 & 0.001 \\
& Kesehatan & & & & \\
2. & Dukungan Suami & 3.470 & 9.007 & 32.140 & 0.003 \\
& Constant & -10.371 & 11.149 & 0.000 & 0.001 \\
\hline
\end{tabular}

Berdasarkan Tabel 10 terlihat bahwa dari pengujian regresi binary logistik hasil multivariat yang paling berpengaruh yaitu fasilitas pelayanan kesehatan dengan nilai $\mathrm{p}=0.001$ dengan OR (57.943) dan dukungan suami nilai $\mathrm{p}=0.003$ dengan OR (32.140)

Tabel 11

Hasil Analisis Regresi Logistik Model Summary

-2 Log likelihood Cox \& Snell R Square Nagelkeker R Square

$31.183^{\mathrm{a}} \quad, 522 \quad, 710$

Berdasarkan Tabel 11 variabel dependen (kunjungan ANC) dengan menggunakan nilai Cox \& Snell $R$ Square dan Nagelkerke $R$ Square. Nilai Cox \& Snell $R$ Square 0,522 dan Nagelkerke $R$ Square sebesar 0,710, yang menunjukkan bahwa kemampuan variabel independen (fasilitas pelayanan kesehatan dan 
dukungan suami) dalam menjelaskan variabel dependen (kunjungan ANC) adalah sebesar 0,710 atau $(71.0 \%)$ dan terdapat $(29.0 \%)$ faktor lain di luar model yang menjelaskan variabel dependen. Atau persamaan regresi variabel independen (fasilitas pelayanan kesehatan dan dukungan suami) secara bersama-sama mempengaruhi variabel dependen (kunjungan ANC) sebesar 71.0\%.

\section{Pengaruh Paritas terhadap Kunjungan ANCdi Puskesmas Alai Kota Padang}

Hasil uji statistik di peroleh nilai p-value 0.035 ( $\mathrm{p}<0,05)$, maka dapat disimpulkan terdapat pengaruh yang bermakna antara paritas dengan kunjungan ANC. Secara kualitatif diketahui bahwa informan 1 merupakan ibu dengan paritas multipara yaitu pernah melahirkan anak sebanyak 2 (dua) kali dan informan 2 juga memiliki paritas primipara yaitu pernah melahirkan anak sebanyak 1 kali.

\section{Pengaruh Pendidikan Terhadap Kunjungan ANC di Puskesmas Alai Kota Padang}

Hasil uji statistik di peroleh nilai p-value 0.001 ( $\mathrm{p}<0,05$ ), maka dapat disimpulkan terdapat hubungan yang bermakna antara paritas dengan kunjungan ANC. Secara kualitatif diketahui bahwa pendidikan terakhir informan 1 dan informan 2 adalah SMA yang memiliki pendidikan menengah. Menurut asumsi peneliti faktor pendidikan cukup mempunyai pengaruh bagi ibu untuk melakukan kunjungan ANC di Puskesmas Alai. Pendidikan berarti bimbingan yang diberikan seseorang kepada orang lain terhadap sesuatu agar mereka dapat memahami.

\section{Pengaruh Pekerjaan Terhadap Kunjungan ANC di Puskesmas Alai Kota Padang}

Hasil uji statistik di peroleh nilai p-value 0.012 ( $\mathrm{p}<0,05)$, maka dapat disimpulkan terdapat pengaruh yang bermakna antara pekerjaan dengan kunjungan ANC. Secara kualitatif diketahui bahwa pekerjaan informan 1 adalah berjualan dan pekerjaan informan 2 adalah ibu rumah tangga (IRT). Dari kedua informan tersebut dapat dilihat bahwa informan 1 bekerja sebagai berjualan sedangkan informan 2 tidak bekerja hanya sebagai ibu rumah tangga.

Menurut asumsi peneliti selama pada diri ibu hamil tersebut masih memiliki keinginan dan perhatian yang lebih terhadap dirinya dan janin, seharusnya tidak akan mempengaruhi frekuensi kunjungan antenatal care walaupun ibu memiliki status sebagai ibu bekerja dan tidak bekerja

\section{Pengaruh Penghasilan Keluarga Terhadap Kunjungan ANC di Puskesmas Alai Kota Padang}

Hasil uji statistik di peroleh nilai p-value 0.806 ( $\mathrm{p}>0,05$ ), maka dapat disimpulkan tidak ada hubungan yang bermakna antara penghasilan keluarga dengan kunjungan ANC. Menurut asumsi peneliti faktor penghasilan keluarga tidak memiliki pengaruh yang signifikan terhadap pelaksanaan antenatal care dikarenakan sesuai dengan 
program pemerintah saat ini bagi masyarakat bukan penerima upah dapat memiliki BPJS yang dapat dimanfaatkan untuk memperoleh pelayanan kesehatan.

\section{Pengaruh Jarak Pelayanan Terhadap Kunjungan ANC di Puskesmas Alai Kota Padang}

Hasil uji statistik di peroleh nilai p-value 0.005 ( $\mathrm{p}<0,05$ ), maka dapat disimpulkan ada hubungan yang bermakna antara jarak pelayanan kesehatan dengan kunjungan ANC. Secara kualitatif diketahui bahwa jarak rumah informan 1 dekat dengan tempat pelayanan kesehatan dan ibu juga tidak membutuhkan alat transportasi untuk sampai ke tempat kesehatan tetapi ibu merasa lelah setelah mencapai tempat pelayanan kesehatan yang dituju yaitu Puskesmas, sedangkan jarak rumah informan 2 jauh dengan tempat pelayanan kesehatan dan membutuhkan alat transportasi hingga bisa sampai ke tempat pelayanan kesehatan tersebut. Informan 5 yaitu bidan juga mengatakan kendala yang dihadapi oleh ibu hamil sehingga tidak mau melakukan kunjungan ANC adalah jarak pelayanan yang jauh yaitu lokasi desa terpencil. Menurut asumsi peneliti, semakin jauh jarak fasilitas kesehatan dari tempat tinggal ibu hamil serta semakin sulit akses menuju ke fasilitas kesehatan akan menurunkan motivasi ibu hamil untuk melakukan kunjungan ANC.

Pengaruh Dukungan Suami Terhadap Kunjungan ANC di Puskesmas Alai Kota Padang

Hasil uji statistik di peroleh nilai p-value 0.002 ( $\mathrm{p}<0,05$ ), maka dapat disimpulkan ada hubungan yang bermakna antara dukungan suami dengan kunjungan ANC. Secara kualitatif diketahui bahwa selama hamil informan 1 tidak pernah ditemani oleh suami apabila melakukan kunjungan pemeriksaan kehamilan yang membuat motivasi ibu menurun untuk melakukan kunjungan ANC, sedangkan informan 2 jauh mengatakan bahwa saat kunjungan kehamilan suami pernah menemani ibu untuk melakukan kunjungan kehamilan tetapi juga pernah ibu pergi sendiri ke Puskesmas atau bidan untuk periksa hamil.

\section{Pengaruh Fasilitas Pelayanan Kesehatan Terhadap Kunjungan ANC di Puskesmas Alai Kota Padang}

Hasil uji statistik di peroleh nilai p-value 0.000 ( $\mathrm{p}<0,05)$, maka dapat disimpulkan terdapat hubungan yang bermakna antara fasilitas pelayanan kesehatan dengan kunjungan ANC. Secara kualitatif informan Bidan pelayanan yang diberikan oleh bidan di Puskesmas Alai sudah sesuai dengan standar, antara lain di dalam memberikan pelayanan bidan sesuai dengan SOP yang ada di Puskesmas dan selalu memperlihatkan keramahan, selalu menanyakan keluhan pasien, menjaga kerahasiaan pasien serta memberikan konseling atas keluhan pasien.

\section{Pengaruh Peran Tenaga Kesehatan Terhadap Kunjungan ANC di Puskesmas Alai} Kota Padang 
Hasil uji statistik di peroleh nilai p-value 0.003 ( $\mathrm{p}<0,05$ ), maka dapat disimpulkan terdapat hubungan yang bermakna antara peran tenaga kesehatan dengan kunjungan ANC. Berdasarkan data secara kualitatif yang dikumpulkan oleh peneliti, dari informan 5, informan 6, informan 7 telah mengupayakan pelayanan kesehatan pada ibu hamil secara maksimal sesuai dengan standar pelayanan minimal yang telah ditetapkan oleh Pemerintah hingga melakukan kunjungan rumah. Tetapi hal tersebut masih belum menjamin terlaksananya pelayanan kesehatan ibu hamil yang optimal. Oleh karena itu diperlukan peningkatan pelaksanaan pelayanan kesehatan ibu hamil yang menyeluruh sehingga tercapainya target cakupan ibu hamil di Puskesmas Alai. Menurut peneliti tenaga kesehatan harus lebih aktif dalam memotivasi ibu untuk melakukan pemeriksaan kehamilan, dan lebih mengarahkan ibu hamil untuk bertindak sebaik mungkin agar menjauhkan diri dari bahaya yang bisa mengancam kehidupan ibu dan janin.

\section{Kesimpulan}

Kesimpulan dalam penelitian ini adalah ada pengaruh paritas, pendidikan, pekerjaan, jarak pelayanan kesehatan, dukungan suami, fasilitas pelayanan kesehatan, peran tenaga kesehatan. Adapun variabel fasilitas pelayanan kesehatan serta dukungan suami merupakan faktor yang paling dominan pengaruhnya terhadap kunjungan ANC. Disarankan kepada Puskesmas Alai agar dapat mengoptimalkan fasilitas pelayanan ibu hamil untuk tercapainya kesejahteraan ibu dan bayi dan suami agar memberikan dukungan kepada ibu hamil untuk melakukan pemeriksaan ANC.

\section{Referensi}

Creswell, J. W. (2010). SAGE Handbook of Mixed Methods in Social \&amp; Behavioral Research (2nd ed.). 2nd ed. https://doi.org/10.4135/9781506335193

Kemenkes RI. (2015). Kesehatan dalam Kerangka Sustainable Development Goals (SDGs). Rakorpop Kementeri Kesehat RI [Internet]. (97):24. Available from: http://www.pusat2.litbang.depkes.go.id/pusat2_v1/wpcontent/uploads/2015/12/SDGs-Ditjen-BGKIA.pdf

Kemenkes RI. (2017). Profil Kesehatan Indonesia. Kemenkes RI. Jakarta; 2017. Dinas Kesehatan Provinsi Sumatera Barat. Profil Dinas Kesehatan Sumatera Barat Tahun 2017. Germas [Internet]. Available from: www.dinkes.sumbarprov.go.id

Kemenkes RI. (2020). Pedoman pelayanan antenatal, persalinan, nifas, dan bayi baru lahir di Era Adaptasi Baru.

Kemenkes, RI. (2013). Riset Kesehatan Dasar. Jakarta: Ministry Of Health.

Prabhakara G. (2020). Health Statistics (Health Information System). Short Textbook of Preventive and Social Medicine. 28-28 p.

Puskesmas Alai (2020). Kunjungan K1 dan K4. In Padang Utara: Puskesmas Alai.

Sumarmi S. (2017). Model Sosio Ekologi Perilaku Kesehatan Dan Pendekatan Continuum of Care Untuk Menurunkan Angka Kematian Ibu. Indones J Public Heal. 12(1):129.

World Health Organization (2018) . WHO, UNICEF, UNFPA, The World Bank Trends In Matrnal Mortality. 